\title{
Growth and characterization of lattice-matched InAIN/GaN Bragg reflectors grown by plasma-assisted molecular beam epitaxy
}

\author{
Ž. Gačević ，S. Fernández-Garrido , E. Calleja , E. Luna , and A. Trampert \\ ISOM and Dpt. de Ingeniería Electrónica, ETSI Telecomunicación, Universidad Politécnica de Madrid, Avda. Complutense s/n, \\ 28040 Madrid, Spain \\ Paul-Drude-Institut für Festkörnerelektronik. Hausvogteinlatz. 5-7. 10117 Berlin. Germanv
}

We demonstrate six to ten period lattice-matched $\mathrm{In}_{0.18} \mathrm{Al}_{0.82} \mathrm{~N} / \mathrm{GaN}$ distributed Bragg reflectors with peak reflectivity centred around $400 \mathrm{~nm}$, grown by molecular beam epitaxy. Thanks to the well-tuned ternary alloy composition crack-free layers have been obtained as confirmed by both optical and scanning electron microscopy. In addition, cross-

1 Introduction High quality distributed Bragg reflectors (DBRs), based on nitride-compounds quarterwave layers, have huge potential for near UV - blue - green vertical cavity devices such as vertical cavity surface emitting lasers, resonant cavity light emitting diodes and Fabry-Perot modulators. Though high-reflectivity DBRs based on both $\mathrm{AlN} / \mathrm{GaN}$ and $\mathrm{Al}_{x} \mathrm{Ga}_{1-\mathrm{x}} \mathrm{N} / \mathrm{Al}_{\mathrm{y}} \mathrm{Ga}_{1-\mathrm{y}} \mathrm{N}$ (for violet-blue-green and near UV applications, respectively) have been already demonstrated the high lattice mismatch between $\mathrm{GaN}$ and AlN binaries remains a key problem to grow high quality III-nitride heterostructures. This mismatch results in strain accumulation leading to plastic relaxation which can be detrimental to optoelectronic devices properties. Recent interest has been focused on the growth of highquality InAlN layers in-plane lattice-matched to GaN. So far, state-of-the-art optoelectronic devices using latticematched InAlN/GaN heterostructures have been grown by metal organic vapour phase epitaxy (MOVPE) exclusively There have been a few reports of molecular beam epitaxy (MBE) growth of InAIN/GaN heterostructures

though their well-controlled growth still remains fundamental challenge. sectional analysis by high resolution transmission electron microscopy reveals highly periodic structure with abrupt interfaces. When the number of DBRs periods increased from six to ten, peak reflectivity increased from $45 \%$ to $60 \%$. This increase was found to be in reasonable agreement with theoretical simulations.
This work reports on the MBE growth and characterization of InAIN single layers and InAIN/GaN DBRs lattice-matched to GaN.

2 Experiment All samples were grown in a RIBER Compact $21 \mathrm{MBE}$ system equipped with a radio-frequency (RF) plasma N source and standard Knudsen cells for gallium, aluminum and indium. As substrates, $\mathrm{GaN}$ templates grown by MOCVD on $c$-plane sapphire were used (Lumi$\log$ ). The growth temperature was measured using an Ircon Modline 3 optical pyrometer and the growth was in-situ monitored by reflection high energy electron diffraction (RHEED). Before the growth of either the InAIN single layers or the DBRs structures, a high-temperature $\left(700^{\circ} \mathrm{C}\right)$ $\mathrm{GaN}$ buffer layer $\sim 100 \mathrm{~nm}$ thick was grown under intermediate Ga-rich growth conditions to bury possible impurities and to provide a smooth and flat surface

The alloy composition was measured by X-ray diffraction (XRD) scans around (0002) Bragg reflection. The crystal quality of the samples was assessed by JEOL JEM 3010 transmission electron microscopy (TEM) and by XRD rocking curve scans. The DBRs reflectivity was 


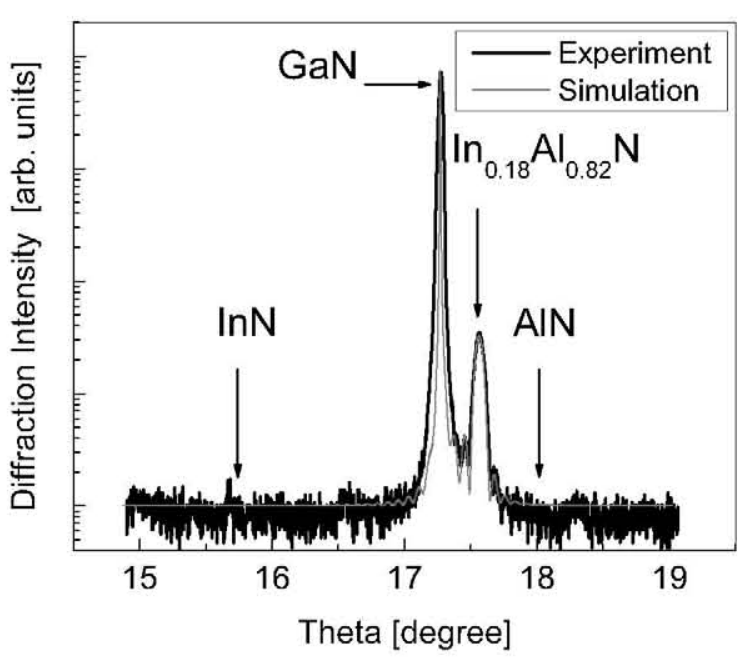

Figure 1 Measured and simulated (0002) $\theta-2 \theta$ XRD spectra of an $\sim 80 \mathrm{~nm}$ thick $\mathrm{In}_{0.18} \mathrm{Al}_{0.82} \mathrm{~N}$ single layer grown on a MOVPE grown $\mathrm{GaN}$ template.

measured at room temperature at normal incidence using a JASCO V-650 spectrophotometer. Data were normalized using a standard calibrating mirror.

3 Results and discussion As a previous step to achieve lattice-matched InAlN/GaN DBRs, MBE grown single InAIN layers were analysed as function of the growth conditions (i. e. substrate temperature and impinging fluxes) InAIN layers lattice-matched to $\mathrm{GaN}$ $\left(18 \%\right.$ In) were successfully grown at $535^{\circ} \mathrm{C}$ near the thermodynamical limit for indium droplets formation using a III/V flux ratio slightly lower than one

Figure 1 shows the typical measured and simulated profiles extracted from the (0002) $\theta-2 \theta$ XRD scan of a $\sim 80 \mathrm{~nm}$ thick $\mathrm{In}_{0.18} \mathrm{Al}_{0.82} \mathrm{~N}$ layer lattice-matched to $\mathrm{GaN}$. Apart from GaN and InAIN (0002) $\theta-2 \theta$ peaks, no additional peaks have been observed confirming that no phase separation occurred during the growth. The full width of half maximum (FWHM) values of rocking curve scans varied within the range of 390 to 420 arcsec indicating a low crystal mosaicity, comparable to that of the underneath $\mathrm{GaN}$ template (approximately 300 arcsec).

A sequence of six to ten period lattice-matched $\mathrm{In}_{0.18} \mathrm{Al}_{0.82} \mathrm{~N} / \mathrm{GaN}$ DBRs was designed with a target wavelength centred at $400 \mathrm{~nm}$. Thus, the nominal thicknesses of InAIN/GaN half-periods were set to 43.5 and $40 \mathrm{~nm}$, respectively. To grow the InAIN half-periods we used the same growth conditions as for the InAIN single layers discussed above. The GaN half-periods were grown at the same temperature $\left(535^{\circ} \mathrm{C}\right)$ close to stoichiometric conditions $(\mathrm{Ga} / \mathrm{N} \sim 1)$ using indium as surfactant. Due to negligible indium desorption at $535^{\circ} \mathrm{C}$, it was required to increase the substrate temperature up to $600{ }^{\circ} \mathrm{C}$ for ten minutes after each GaN half-period to allow for desorption of indium droplets formed during the growth of the GaN layers.

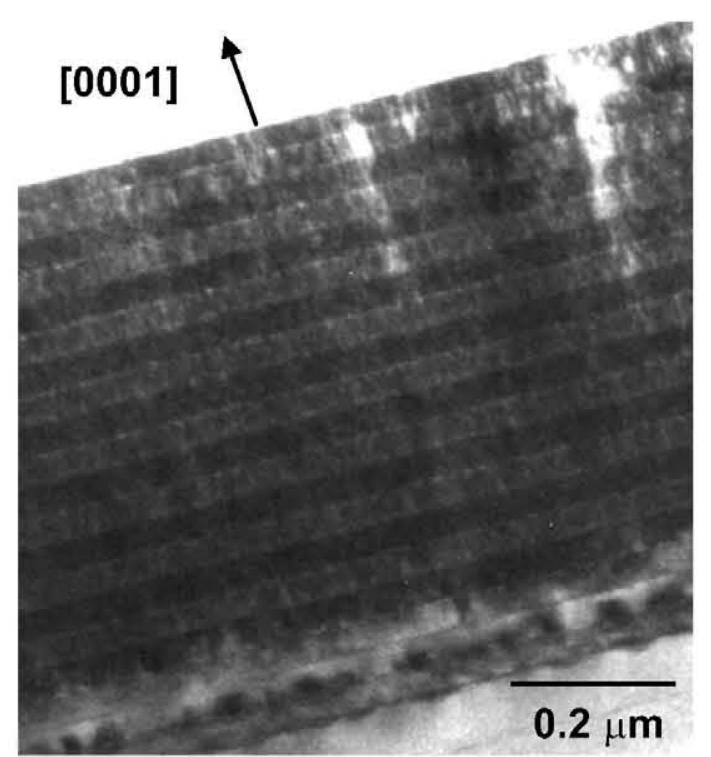

Figure 2 TEM cross-sectional view of a ten period latticematched InAlN/GaN DBR. Dark layers are GaN while light ones are InAIN.

During the growth of InAIN half-periods, the RHEED pattern was getting slightly streaky-modulated but recovered within tens of seconds during the $\mathrm{GaN}$ half-period growth. Additionally, the RHEED pattern was found to be somewhat dimmer at the end of each period. That was a consequence of a slight accumulation of droplets on the sample surface, as confirmed by optical microscopy. This points to indium droplets acumulation due to excess of indium not fully desorbed after each GaN half-period. No cracks were observed by either optical or scanning electron microscopy on the samples surface. Additionally, crosssectional TEM images revealed the absence of micro cracks. The bright field TEM micrograph in Fig. 2 reflects the high periodicity of the InAIN/GaN DBR and the abrupt

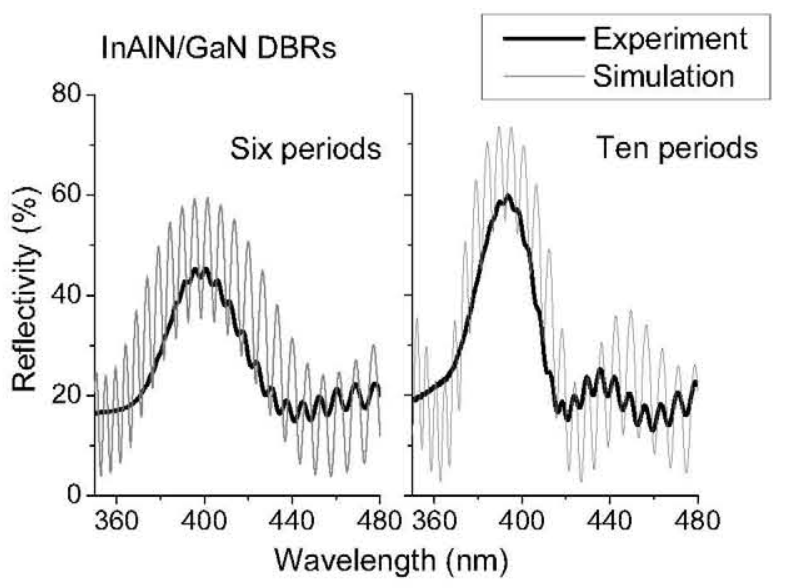

Figure 3 Measured and simulated reflectivity of six- and tenperiod $\mathrm{In}_{0.18} \mathrm{Al}_{0.82} \mathrm{~N} / \mathrm{GaN}$ DBRs. 
interfaces with no indications of extended phase separated precipitates.

Normalized reflectivity spectra of six and ten period DBRs are summarized in Fig. 3. Experimental data show that when the number of periods increased from six to ten, the peak reflectivity increased from $45 \%$ to $60 \%$. The $60 \%$ reflectivity is significantly higher than the value reported by Ive et al. found to be around $38 \%$ for eleven-period InAlN/GaN DBR centred at $450 \mathrm{~nm}$ (also grown by MBE). It was speculated that such low reflectivity was obtained due to residual absorption and/or scattering by In-rich regions on submicroscopic scale. However, $60 \%$ reflectivity is still inferior to $76 \%$ reflectivity reported by Carlin et al

for a ten-period InAIN/GaN DBR centred at $455 \mathrm{~nm}$ (grown by MOVPE). Thus we suppose that although residual absorption dramatically decreased when compared to results reported by Ive it is still somewhat present in our grown samples.

To interpret the reflectivity results, a transfer matrix method was applied to simulate the structure. The absorption in DBR layers was neglected and the thick sapphire substrate was assumed to be infinite. We found that simulation data were in best agreement with recorded spectra when refractive indexes of 2.34/2.5 for InAlN/GaN layers respectively were used. However, the refractive index contrast between the two materials is widely reported to be between $7-8 \%$ in the violet-blue range which is slightly higher than $6.4 \%$ value used in our simulation. This disagreement can also be explained by actual presence of residual absorption supposed to be zero in the simulations.

4 Conclusion In summary, we have demonstrated the growth of both $\mathrm{In}_{0.18} \mathrm{Al}_{0.82} \mathrm{~N}$ single layers and $\mathrm{In}_{0.18} \mathrm{Al}_{0.82} \mathrm{~N} / \mathrm{GaN}$ based DBRs lattice-matched to $\mathrm{GaN}$ by MBE. $\mathrm{In}_{0.18} \mathrm{Al}_{0.82} \mathrm{~N}$ single layers show a crystal mosaicity comparable to that of the underneath $\mathrm{GaN}$ template with minimal FWHM values of the $(0002)$ rocking curve scans of 390 aresec. The $\operatorname{In}_{0.18} \mathrm{Al}_{0.82} \mathrm{~N} / \mathrm{GaN}$ based DBRs show high periodicity and abrupt interfaces. The increase in reflectivity from $45 \%$ ( 6 periods) to $60 \%$ (10 periods) is found to be in reasonable agreement with theoretical simulations. However, the total reflectivity of $60 \%$ of tenperiod lattice-matched DBR is still lower than the expected value $(>70 \%)$. The background reason for this finding could be the presence of residual absorption by defects in our samples. Further work is required to confirm the actual origin of this discrepancy.

\section{References}

H. M. Ng, D. Doppalapudi, E. Iliopoulos, and T. D. Moustakas, Appl. Phys. Lett. 74, 1036 (1999).

O. Mitrofanov, S. Schmult, M. J. Manfra, T. Siegrist, N. G. Weimann, A. M. Sergent, and R. J. Molnar, Appl. Phys. Lett. 88, 171101 (2006).

J. F. Carlin and M. Ilegems, Appl. Phys. Lett. 83, 668 (2003).

E. Feltin, R. Butte, J.F. Carlin, J. Dorsaz, N. Grandjean, and M. Ilegems, Electron. Lett. 41, 94 (2005).

S. Nicolay, J.F. Carlin, E. Feltin, R. Butté, M. Mosca,

N. Grandjean, and M. Ilegems, Appl. Phys. Lett. 87, 111106 (2005).

E. Feltin, G. Christmann, J. Dorsaz, A. Castiglia, J. F. Carlin, R. Butte, N. Grandjean, S. Christopoulos, G. Baldassarri Hoger von Hogersthal, A. J. D. Grundy, P. G. Lagoudakis, and J. J. Baumberg, Electron. Lett. 43, 924 (2007).

M. Higashiwaki, T. Mimura, and T. Matsui, Jpn. J. Appl. Phys. Part 2 45, L843 (2006).

S. Schmult, T. Siegrist, A. M. Sergent, M. J. Manfra, R. J. Molnar, Appl. Phys. Lett. 90, 021922 (2007).

T. Ive, O. Brandt, X. Kong, A. Trampert, and K. H. Ploog, Phys. Rev. B 78, 035311 (2008).

B. Heying, R. Averbeck, L. F. Chen, E. Haus, H. Riechert, and J. S. Speck, J. Appl. Phys. 88, 1855 (2000).

S. Fernández-Garrido, Ž. Gačević, and E. Calleja, Appl. Phys. Lett. (to be published).

A. Thelen, Design of Optical Interference Coatings, McGraw-Hill Optical and Electro-Optical Engineering Series (McGraw-Hill, New York, 1989). 